\title{
MENINGKATKAN MOTIVASI WARGA KELURAHAN BAKTIJAYA DEPOK UNTUK MELAKUKAN PENJUALAN MELALUI E-COMMERCE
}

\author{
Anizar Rahayu \\ Prodi Doktor Psikologi, Fakultas Psikologi UPI YAI \\ e-mail: anizar.rahayu@upi-yai.ac.id
}

\begin{abstract}
Abstrak
Perkembangan teknologi khususnya komputer dan telekomunikasi sangat mendukung pelaku bisnis dalam menjalankan usahanya, terutama kecepatan dalam mengakses informasi sangat menunjang aktivitas bisnis di tahun - tahun terakhir ini. Penggunaan internet dalam bisnis berubah fungsi yang semula sebagai alat pertukaran informasi secara elektronik, berubah menjadi alat untuk mengakses aplikasi strategi bisnis seperti pemasaran, penjualan, pelayanan kepada pelanggan dan sebagainya. Namun demikian pada kenyataannya, masih banyak pelaku bisnis kecil yang menjalankan usahanya dengan cara tradisional, karena itu penyuluhan ini dilakukan untuk memberikan pengetahuan tentang e-commerce dan dorongan semangat kepada ibu-ibu rumah tangga sebagai pelaku usaha home industry. Peserta penyuluhan adalah ibu-ibu rumah tangga warga Kelurahan Baktijaya Depok Jawa Barat yang memiliki usaha rumahan. Materi penyuluhan berupa pengetahuan tentang e-commerce dan motivasi. Hasil yang diharapkan setelah mengikuti penyuluhan ini adalah adanya peningkatan pengetahuan tentang $e$ commerce dan peningkatan motivasi peserta dalam mengembangkan usahanya. Adapun hasil yang diperoleh dari kegiatan ini yaitu terjadi peningkatan pengetahuan terkait $e$-commerce dan peserta menjadi termotivasi dalam mengembangkan usahanya melalui e-commers.
\end{abstract}

Kata Kunci: E-Commerce, Motivasi, Home Industry

\begin{abstract}
The development of technology, especially computers and telecommunications, has greatly supported business people in running their business, especially the speed in accessing information has greatly supported business activities in recent years. The use of the internet in business has changed its function which was originally as a means of exchanging information electronically, turning into a tool for accessing business strategy applications such as marketing, sales, customer service and so on. However, in reality, there are still many small business people who run their business in the traditional way, therefore this counseling is carried out to provide knowledge about e-commerce and encourage housewives as home industry business actors. The counseling participants were housewives, residents of Baktijaya Village, Depok, West Java, who had home-based businesses. The counseling material is in the form of knowledge about e-commerce and motivation. The expected result after attending this counseling is an increase in knowledge about e-commerce and an increase in the motivation of participants in developing their business. The results obtained from this activity are an increase in knowledge related to e-commerce and participants become motivated in developing their business through e-commerce.
\end{abstract}

Keywords: e-commerce, motivation, home industry

\section{PENDAHULUAN}

Seiring dengan perkembangan teknologi yang cukup pesat, yang selanjutnya diikuti pula perkembangan industry e-commerce di Indonesia. Hal ini terlihat dari data statistik BPS tahun 2019 yang menyatakan bahwa industri e-commerce dalam 10 tahun terakhir meningkat hingga $17 \%$ dengan total jumlah usaha e-commerce mencapai 26,2 juta unit (www. wartaekonomi.co.id). Efektivitas dan efisiensi jelas menjadi sebuah prioritas utama yang harus dipertimbangkan oleh para pihak yang melakukan jual 
beli, terlebih oleh pihak-pihak pelaku ekonomi seperti sebuah perusahaan karena dengan semakin efektif dan efisien suatu pekerjaan dilakukan maka keunntungan akan semakin banyak didapatkan. Efisiensi dalam penjualan ini sangat memungkinkan ketika penggunaan e-commerce diterapkan dalam proses penjualan.

E-commerce merupakan wujud kemajuan teknologi pada aspek bisnis yang memadukan antara mekanisme konvensional dan digital. E-commerce pada transaksi bisnis berbasis individu ataupun perusahaan digerakkan sebagai medium pertukaran barang, jasa dan informasi baik antara dua buah isntitusi (business to business) dan konsumen langsung (business to consumen). Singkatnya, e-commerce saat ini bisa dilihat sebagai alternatif dalam menjalankan transaksi bisnis yang syarat dengan solusi berupa kemudahaan yang selama ini menjadi persoalan dominan (Suparni, 2009 dalam Rosyita, 2018).

Penjual Indonesia yang menggunakan $e$-commerce sebagai media atau alat untuk menjual produknya cukup banyak. Hal tersebut menunjukkan bahwa masyarakat telah dapat mengakses dan memanfaatkan $e$ commerce. E-commerce dapat diakses masyarakat melalui beberapa aplikasi yang tersedia dalam gawai, seperti melalui aplikasi Shopee, Tokopedia, Buka Lapak, dan lain-lain. Masyarakat juga dapat mengakses e-commerce ini melalui whatsapp, Instagram, dan facebook, maupun aplikasi lainnya yang dapat mengakses e-commerce. Usaha yang dijalani melalui metode atau model baru ini tidak hanya diakses masyarakat menengah ke atas namun dapat diakses juga oleh masyarakat kelas menengah ke bawah, karena harga yang ditawarkan penjual satu dengan yang lainnya beragam dan mampu menjangkau seluruh komponen masyarakat.

Wirausahawan adalah orang yang berani membuka kegiatan produktif yang mandiri dan salah satu karakter yang sangat penting dimiliki adalah kemampuannya berinovasi. Tanpa adanya inovasi perusahaan tersebut tidak akan bertahan lama. Adapun alasan inovasi penting untuk dilakukan antara lain: 1). Teknologi berubah sangat cepat seiring adanya produk baru, proses dan layanan baru dari pesaing, dan ini mendorong usaha entrepreneurial untuk bersaing dan sukses. Yang harus dilakukan adalah menyesuaikan diri dengan inovasi teknologi baru. 2). Efek perubahan lingkungan terhadap siklus hidup produk semakin pendek, yang artinya bahwa produk atau layanan lama harus digantikan dengan yang baru dalam waktu cepat, dan ini bisa terjadi karena ada pemikiran kreatif yang me-nimbulkan inovasi. 3). Konsumen saat ini lebih pintar dan menuntut pemenuhan kebutuhan. Harapan dalam pemenuhan kebutuhan mengharap lebih dalam hal kualitas, pembaruan, dan harga. Oleh karena itu skill inovatif dibutuhkan untuk memuaskan kebutuhan konsumen sekaligus mempertahankan konsumen sebagai pelanggan. 4). Dengan pasar dan teknologi yang berubah sangat cepat, ide yang bagus dapat semakin mudah ditiru, dan ini membutuhkan metode penggunaan produk, proses yang baru dan lebih baik, dan layanan yang lebih cepat secara kontinyu. 5). Inovasi bisa menghasilkan pertumbuhan lebih cepat, meningkatkan segmen pasar, dan mencipta-kan posisi korporat yang lebih baik (Seprina, Suroyo, dan Komalasari, 2018).

Keunggulan dan kemajuan perusahaan atau suatu usaha akan terwujud jika memiliki sumber daya manusia yang unggul pula sehingga akan menghasilkan kinerja yang baik dan tepat. Selain hal tersebut, motivasi atau semangat kerja juga mempengaruhi kinerja karyawan sehingga semakin tinggi motivasi kerja maka semakin tinggi pula kinerja karyawan (Afandi, 2021).

Berdasarkan hasil penelitian sebelumnya yang telah dilakukan oleh Seprina, Suroyo, dan Komalasari (2018) yang menguji pengaruh efektivitas penggunaan e-commerce pada peningkatan motivasi berwirausaha pada siswa SMK Bina Jaya Palembang, diperoleh hasil bahwa terdapat perbedaan motivasi siswa yang menggunakan e-commerce dalam berwirausaha antara kelompok responden yang sudah memiliki akun e-commerce dengan yang belum.

Wibowo (2014) bahwa perusahan e-commerce tidak hanya mengandalkan produknya saja untuk bertahan, tetapi juga dibutuhkan tim manajemen yang handal, pengiriman tepat waktu, pelayanan yang bagus, struktur organisasi bisnis yang baik, jaringan infrastruktur dan keamaan, desain situs web yang bagus, beberapa faktor termasuk: 1). Menyediakan harga kompetitif. 2). Menyediakan jasa pembelian 
yang tanggap, cepat, dan ramah. 3). Menyediakan informasi barang dan jasa yang lengkap dan jelas. 4). Menyediakan banyak bonus. 5). Memberikan perhatian khusus seperti usulan pembelian. 6). Menyediakan rasa komunitas untuk berdiskusi, masukan dari pelanggan. 7). Mempermudah kegiatan perdagangan.

Berdasarkan hasil observasi di masyarakat RW 04 Kelurahan Baktijaya ditemukan adanya beberapa permasalahan, antara lain: a). Belum termotivasi Warga RW 04 Kelurahan baktijaya untuk menjual dan memasarkan produknya melalui e-commerce. b) Masih ada Warga RW 04 yang memiliki usaha rumahan yang belum mengerti tentang E-commerce dan Market Place. c). Masih ada Warga RW 04 yang memiliki usaha rumahan memasarkan produknya Dari mulut ke mulut. Oleh karena itu, dalam upaya meningkatkan penjualan dan pendapatan warga yang memiliki usaha rumahan, solusi yang dapat diberikan yaitu dengan memberikan edukasi yang bertujuan untuk meningkatkan pengetahuan warga tentang e-commerce sehingga warga akan termotivasi lebih dalam mengembangkan usaha rumahan yang dimiliki.

\section{METODE}

Pelaksanaan pada kegiatan pengabdian kepada masyarakat dari persiapan hingga pelaporan kegiatan dilakukan selama 3 bulan. Adapun metode yang digunakan yaitu berupa penyuluhan. Berikut ini tahapan kegiatan pengabdian kepada masyarakat, digambarkan pada roadmap berikut:

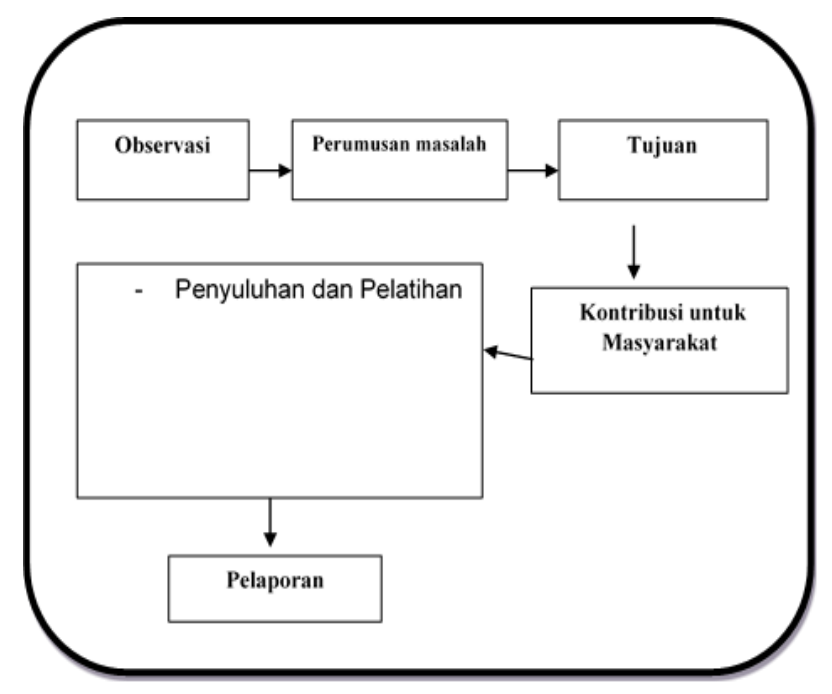

Gambar 1. Road Map kegiatan Pengabdian Masyarakat

Adapun deskripsi dari kegiatan tersebut adalah sebagai berikut:.

1. Observasi Lapangan

Pengabdian pada masyarakat merupakan kegiatan yang dilakukan seorang dosen di luar kampus dan merupakan kewajiban yang harus dilakukan untuk tiap-tiap semester. Oleh karena itu setelah berdikusi dengan beberapa orang warga yang difasilitasi oleh ketua RW, maka penulis bermaksud melakukan pengabdian masyarakat di Kantor RW 04 Kelurahan Baktijaya Depok dengan tema Meningkatkan Penjualan Melalui E-commerce untuk Usaha Rumahan Warga Kelurahan Baktijaya, Depok.

2. Kegiatan Penyuluhan

Pelaksanaan kegiatan pengabdian pada masyarakat dilaksanakan di Kantor RW 04 Kelurahan Baktijaya. Jl. Lematang 3 RT 001 RW 04 dengan peserta Warga RW 04 Kelurahan Baktijaya yang memiliki usaha rumahan. 
Peserta kegiatan ini adalah ibu-ibu warga yang memiliki usaha rumahan di RW 04 Kelurahan Baktijaya Depok. Kegiatan dilaksanakan di Kantor RW 04. Adapun materi yang disampaikan yaitu terkait e-commerce dan motivasi dalam pengembangan usaha rumahan (home industry). Adapun materi yang disampaikan yaitu terkait e-commerce dan motivasi dalam pengembangan usaha rumahan (home industry). Diharapkan warga dapat termotivasi dan tertarik untuk melakukan pemasaran dan penjualan melalui e-commerce sehingga terjadi peningkatan pendapatan keluarga.

\section{HASIL DAN PEMBAHASAN}

Kegiatan pengabdian kepada masyarakat ini dilaksanakan pada tanggal 23 Mei 2019 dan berlangsung dari jam 12.20 sampai 17.00 WIB. Kegiatan penyuluhan ini dilakukan secara tatap muka. Pada penyuluhan ini instruktur yaitu dosen Universitas Persada Indonesia YAI. Kegiatan penyuluhan ini dihadiri oleh 28 orang ibu-ibu yang memilihi usaha di rumah. Materi yang disampaikan pada penyuluhan ini dibagi menjadi dua tahapan yaitu pembahasan tentang e-commerce dan motivasi. Selanjutnya diikuti dengan tanya jawab dan evaluasi terkait capaian yang diperoleh.

Sebelum kegiatan penyuluhan dimulai, terlebih dahulu dilakukan pembukaan acara sekaligus pemberian kata sambutan oleh Ketua RW 04. Kelurahan Baktijaya Bapak Untung Soenaryo. Dalam Sambutannya Bapak Untung Soenaryo berpesan pada peserta agar apa yang sampaikan oleh Dosen-dosen YAI dapat difahami dan dijalankan.

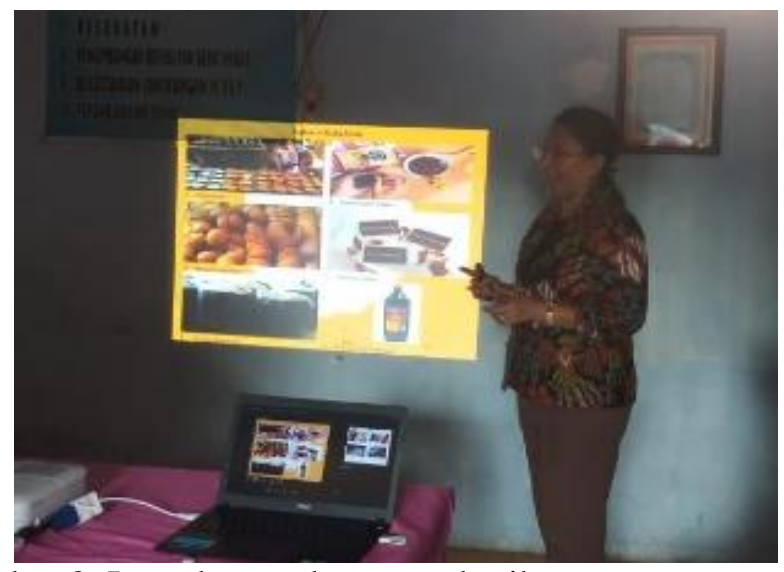

Gambar 2. Instruktur sedang memberikan pemaparan materi

Pada gambar 2, instruktur yang merupakan Dosen Fakultas Psikologi Universitas Persada Indonesia Y.A.I sedang memaparkan materi pelatihan e-commerce dan motivasi dalam meningkatkan usaha. Sebelum melakukan pemaparan materi, terlebih dahulu instruktur menanyakan sejauh mana peserta mengetahui tentang e-commerce dan ternyata seluruh peserta tidak mengetahui tentang hal ini.

Dalam proses pemaparan, instruktur sangat terbuka dengan pertanyaan-pertanyaan yang diajukan oleh peserta. Terjadi komunikasi yang interaktif, dimana ketika peserta kurang memahami terkait materi yang disampaikan, peserta langsung bertanya kepada instruktur tanpa menunggu sesi tanya jawab. Hal ini terjadi karena para peserta sangat awam dengan kemajuan teknologi sehingga banyak istilah-istilah yang belum pernah mereka dengar. Walaupun sudah ada beberapa ibu yang telah punya atau sedang merintis usaha rumahan.

Di akhir sesi penyuluhan, instruktur melakukan evaluasi terhadap pengetahuan peserta tentang $e$ commerce dengan memberikan pertanyaan - pertanyaan atau contoh langkah - langkah yang bisa di ambil oleh peserta penyuluhan dan hasilnya menunjukkan bahwa sebagian peserta cukup memahami apa yang dimaksud dengan e-commerce dan bagaimana melakukan. Selain itu, secara keseluruhan peserta termotivasi melakukan pengembangan usahanya dengan menggunakan strategi e-commerce ini. 


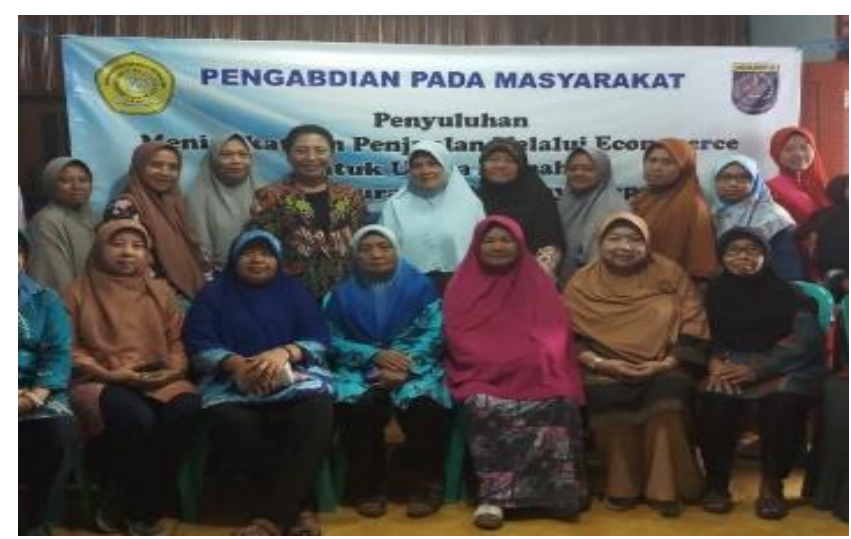

\section{SIMPULAN}

Gambar 3. Foto Bersama Instruktur dan Peserta

Berdasarkan evaluasi yang dilakukan terkait pelaksanaan penyuluhan dalam rangka pengabdian masyarakat dapat ditarik kesimpulan bahwa telah terjadi peningkatan pengetahuan peserta dalam memahami strategi pemasaran e-commerce dan terjadi peningkatan motivasi peserta untuk mengembangkan home industry yang mereka miliki. Dengan memperhatikan minat peserta yang cukup besar dalam mengikuti pelatihan ini maka disarankan perlu dilaksanakan kegiatan sejenis pada kelurahan atau kecamatan lainnya.

\section{SARAN}

Strategi e-commerce penting untuk dilakukan dalam upaya pengembangan usaha yang dimiliki. Saran untuk PKM selanjutnya mungkin bisa diadakan pelatihan tentang manajemen keuangan untuk bisnis kecil sehingga warga dapat mengelola keuangan hasil usahanya dengan maksimal.

\section{UCAPAN TERIMAKASIH}

Kami tim kegiatan pengabdian masyarakat ini mengucapkan terima kasih kepada Ketua RW 04. Kelurahan Baktijaya yang telah memberikan kesempatan kepada kami untuk melakukan penyuluhan pada warga RW 04 yang memiliki usaha di rumah.

\section{DAFTAR PUSTAKA}

Afandi, M. 2021. E-Commerce Dorong Perekonomian Indonesia, Selama Covid 19 sebagai Entrepreneur Modern.https://www.researchgate.net/publication/350525033_E-

Commerce_dorong_perekonomian_Indonesiaselama_covid_19_sebagai_entrepreneur_modern.

Rosyita, E. 2018. Efektivitas E-commerce dalam Meningkatkan Penjualan di Toko Komputer "EG Computer" Purwokerto. (Skripsi). Jurusan Ekonomi Syari'ah Fakultas Ekonomi dan Bisnis Islam Institut Agama Islam Purwokerto. http://repository.iainpurwokerto.ac.id/5065/1/COVER_BAB\%20I_BAB\%20V_DAFTAR\%20PU STAKA.pdf

Seprina, I., Suroyo, H, dan Komalasari, D. 2018. Pengaruh Efektivitas Penggunaan E-Commerce pada Peningkatan Motivasi Berwirausaha pada Siswa SMK Bina Jaya Palembang. Jurnal Sistem Informasi, Teknologi Informatika dan Komputer. 8(2), p-ISSN 2089-0265, eISSN 2598-3016. Hal. 90-96.

Wibowo, E.A. 2014. Pemanfaatan Teknologi E-commece dalam Proses Bisnis. Jurnal Equilibiria. 1(1). Hal. 95 - 108 